\title{
The study of recovery behaviors of different types of Styrene Butadiene Rubber after aging using circular deformation
}

\author{
Sanaa M. Al-Delaimy \\ Department of Physics / College of Education \\ University of Mosul
}

Received

04 / 08 / 2009
Accepted

02 / $11 / 2009$

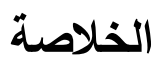

اجري في هذا البحث اختبار قابلية أنواع مختلفة من مادة مطاط الستايرين بيوتادايين (SBR)

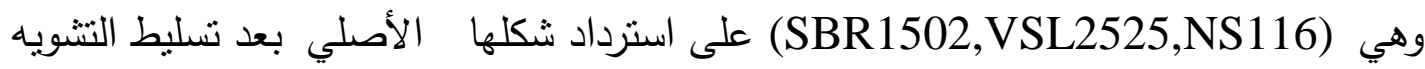
الدائري عليها وبظروف تعتيق مختلفة من فنرات زمنية ودرجات حرارة وتمت المقارنة بين سلوكها وقابليتها على استرداد شكلها ضمن الظروف الفئ المدروسة. خضعت جميع النماذج الى اختبار التشويه الدائري لفترات مختلفة بدرجة حرارة الغرفة وكذلك بدرجات حرارة مختلفة وتم قياس نسبة الاسترداد بعد إزالة النتويه. ووجد بانه يزداد بزيادة الزمن

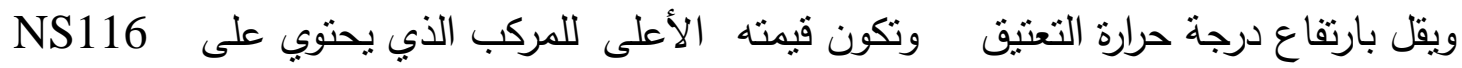
والأدنى للمركب الذي يحتوي على SBR1502.

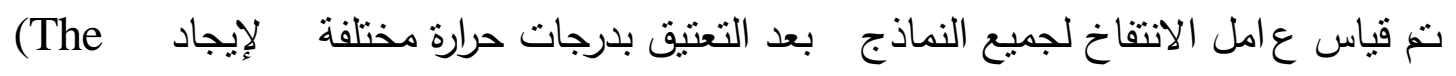
apparent crosslink density)

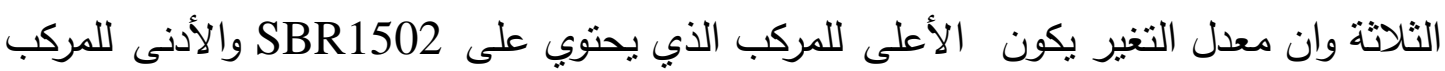

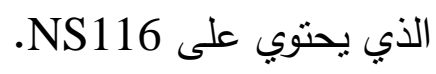

\footnotetext{
Abstract

Recovery behaviors from circular deformation of styrene butadiene rubber were studied at different aging circumstances. SBR1502, VLS2525, NS116, were the material used to make different types of SBR. Circular deformation was done on all samples at different periods and temperatures.

Recovery percent was measured and found that it was increased with deformation time and decreased with aging temperature increment and it was the highest for NS116 and the lowest for SBR1502.
} 
Also the apparent crosslink density was measured and found that it was increased with aging temperature for the three types rubber and the rate of its variation was the highest for SBR1502 and the lowest for NS116.

\section{Introduction}

Rubber is used in many products including tires, belts, tubes, sealant, wire, covering materials, and so on, depending on the advantage of its excellent elasticity, restorability and flexibility. Other properties like abrasion resistivity, oil resistivity, heat resistivity and electrical resistivity are also required of rubber depending on it application [1].

Styrene-butadiene rubber (SBR) is a copolymer of styrene and butadiene, the butadiene has three different microstructures of cis-1.4- , trans-1.4, and 1,2-units. The 1,2-unit has one allylic carbon which is hindered by the vinyl group where as the cis-1,4- and trans -1,4- units have two allylic carbons (as in sketch-1).

\section{$\mathrm{CH} 2=\mathrm{CH}-\mathrm{CH}=\mathrm{CH} 2 \mathrm{CH} 2=\mathrm{CH}-\mathrm{CH}-\mathrm{CH} 3 \mathrm{CH} 2-\mathrm{CH}=\mathrm{CH}-\mathrm{CH} 2$}

n-Butadiene 1,2-unit cis-1,4- and trans-1,4-units

\section{Sketch-1: Chemical formulas of the butadiene types}

Fillers play an important role in changing the mechanical properties (Hardness, Toughness, etc.) due to the strong polymer-filler interaction, which leads to improve the wet-skid resistance [2,3]. Carbon black and silica are the most popular reinforcing fillers in rubber compounds. Carbon black is added as the reinforcement agent to rubber for car tires that must have abrasion resistance, while silica is used as agent to increase the insulation of rubber[1].

Silica has a number of hydroxyl groups (silanol, $\mathrm{Si}-\mathrm{OH}$ ), which results in strong filler-filler interactions and adsorption of polar materials by hydrogen bonds [4]. Since intermolecular hydrogen bonds between silanol groups on silica surface are very strong, it can aggregate tightly [5, 6].

Deformation can be done permanently in rubber when they are deformed by any external stress for long time, especially in high temperature. One of principle reasons about permanent deformation is change of crosslink density [7]. Crosslink density of rubber is changed by thermal aging [8]. A rubber material has a recovery property to return to its original shape from deformation [9]. Degree of the instantaneous recovery is related with the sealing capability of sealant such as O-ring [10]. Many researches have been done on thermal aging to discover its effect on physical properties of rubber with different kind of fillers specially the sealing properties of sealant used rubber $[8,11,12]$.

The aim of this work is to study the effect of aging on deformation recovery percent, instantaneous recovery percent and apparent crosslink density of different types of silica-reinforced styrene-butadiene rubber (SBR) at different times and temperatures. 


\section{Experimental work}

Material used in this work was supplied by Jabber-Bin-Hayyan company. SBR1502, VSL2525 and NS116 were used as different types of styrene butadiene rubber, reinforced by silica and the national standard additives. The three types of SBRs have different 1,2-unit content of 18,25 , and $60 \mathrm{wt} \%$ respectively. Sheets of this product were prepared with dimension $(12 \times 10 \times 0.2) \mathrm{cm}$ and used directly after production in the following tests.

For the study of deformation recovery percent, a sheet was cut into strip-like samples with $(5 \times 120) \mathrm{mm}$ and $2 \mathrm{~mm}$ thickness. Each sample was changed to a circular form by turning it loosely around circular solid material and fixing both ends with a pin. Group of samples with circular form were aged for $(7,15,30)$ days at room temperature another group were aged for 7 days at $(50,60,70,80){ }^{\circ} \mathrm{C}$. All samples were released and the distance $\left(\mathrm{d}_{\mathrm{f}}\right)$ between both ends of each sample was measured after $(0.08,0.25,1,2.5,5,10,24,48,72) \mathrm{hr}$ starting from removing the pin from both ends of each sample. To calculate the deformation recovery percent $(\mathrm{R} \%)$ the following equation was used:

$$
\mathrm{R} \%=100 \frac{\mathrm{d}_{\mathrm{f}}}{\mathrm{d}_{\mathrm{o}}}
$$

Where $\mathrm{d}_{\mathrm{f}}$ : is the gap distance after the deformation, $\mathrm{d}_{\mathrm{o}}$ : is the length of the linear sample (as in sketch-2).

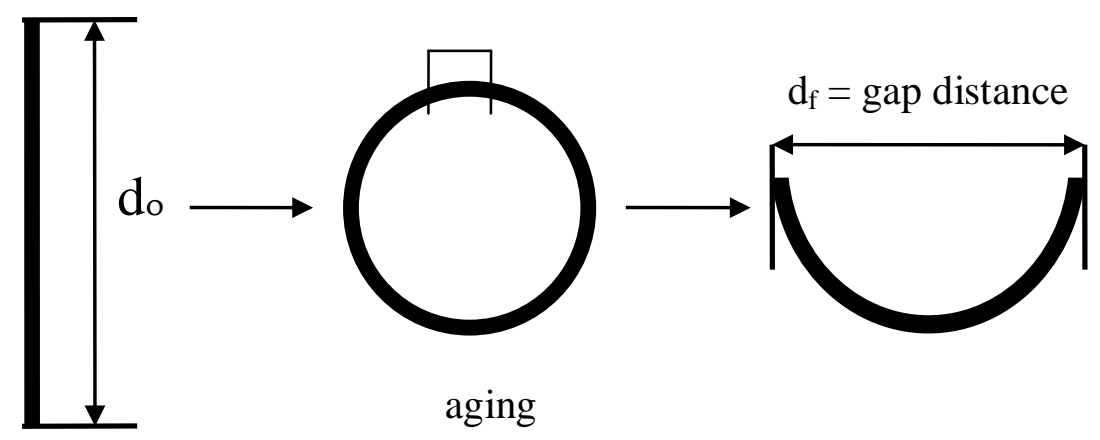

Sketch-2: steps of circular deformation and recovery experiment

The apparent crosslink density of the samples before and after aging, was calculated from the equilibrium swelling (Q). Q was carried out according to the standard swelling method [13]. Organic additives in the samples were removed by extracting with THF and n-hexane, and they were dried for 2 days at room temperature. The weights of the organic material-extracted samples were measured $\left(\mathrm{W}_{\mathrm{d}}\right)$. They were dipped in toluene for 2 days and the weights of swollen samples were measured $\left(\mathrm{W}_{\mathrm{s}}\right)$. The swelling ratio $(\mathrm{Q})$ was calculated by using the following equation: 


$$
\mathrm{Q}=\frac{\mathrm{W}_{\mathrm{s}}-\mathrm{W}_{\mathrm{d}}}{\mathrm{W}_{\mathrm{d}}}
$$

The reciprocal of swelling ratio (1/Q) was used as the apparent crosslink density.

\section{Results and Discussions}

Recovery behaviors from the circular form of SBR1502, VSL2525, and NS116 after aging at room temperature for 7, 15 and 30 days were investigated. Figures 1,2 and 3 show the variation of recovery percent (R\%) of the three types of SBR compound aged for 7,15 and 30 days respectively versus the time after the removal from the circular form.

It is clear that $\mathrm{R} \%$ increases with the time increment after releasing the samples from the circular form in all figures. The comparison between the magnitude of recovery in the three figures shows that $\mathrm{R} \%$ becomes lower with the increase of aging period, and it is for (NS116>VSL2525 >SBR1502) in all periods of aging.

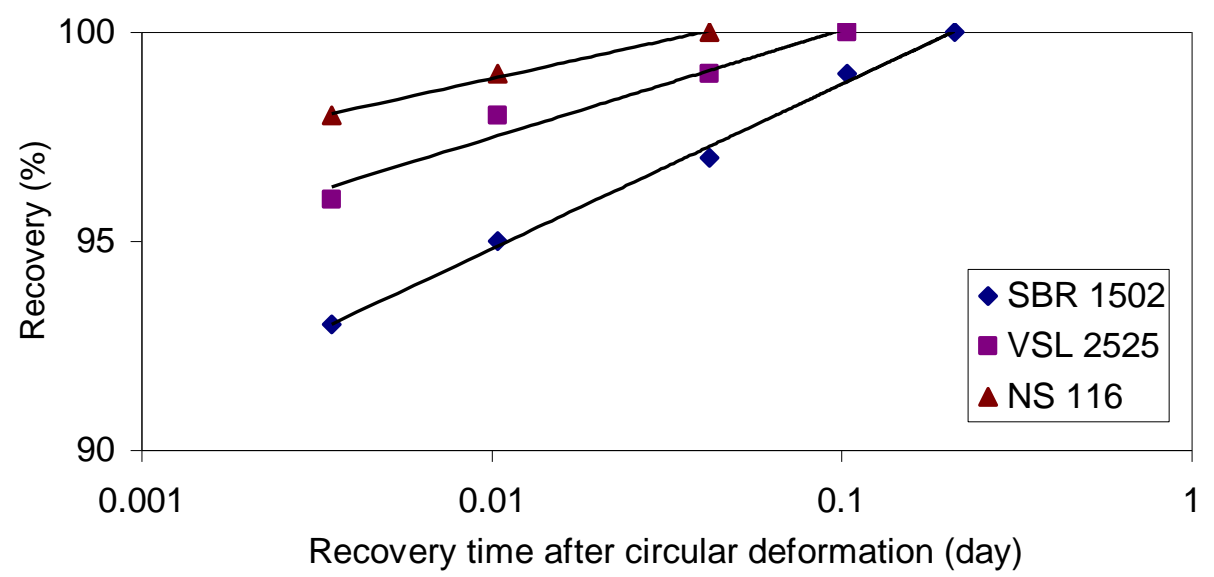

Fig.(1) Recovery percent for different types of SBR aged for 7 days at room temperature

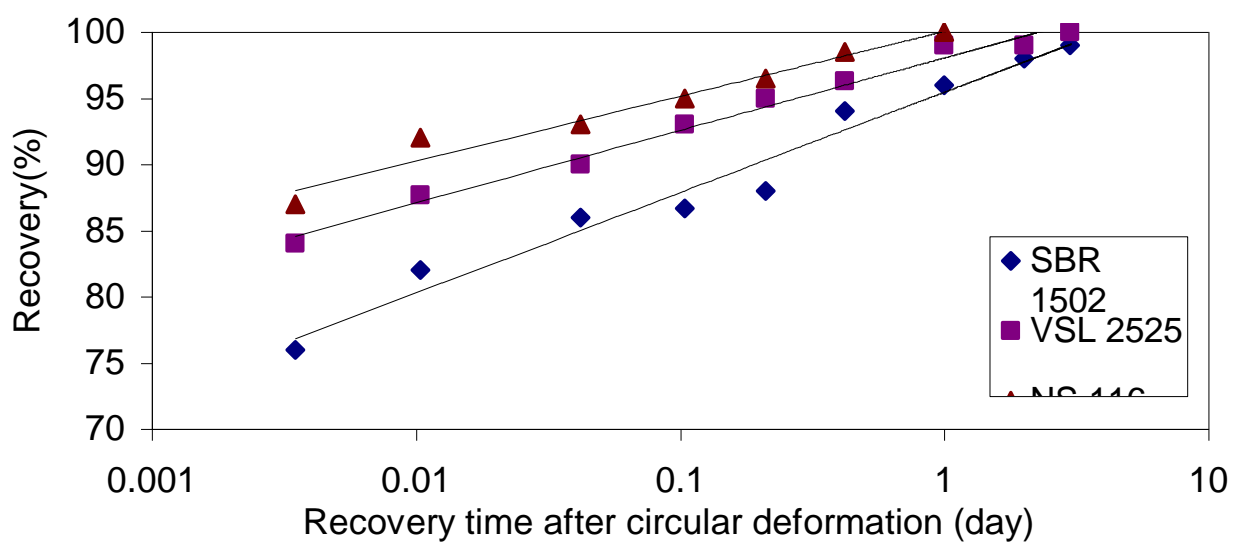

Fig.(2) Recovery percent for different types of SBR aged for 15 days at room temperature 


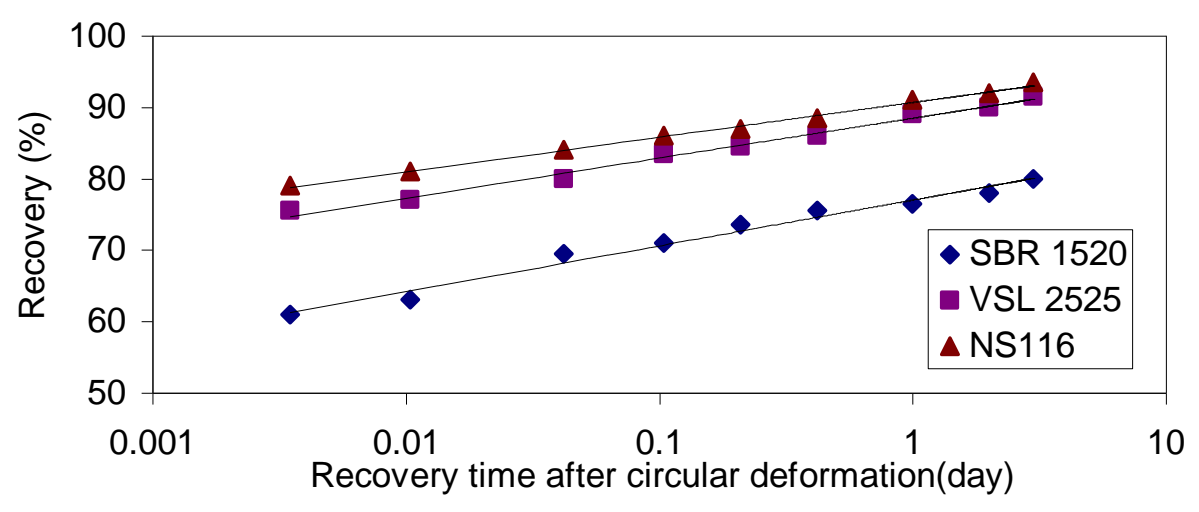

Fig.(3) Recovery percent for different types of SBR aged for 30 days at room temperature

This can be explained by the crosslink densities. A rubber material with higher crosslink density has higher modulus and is stiffer than that with lower one [14]. A rubber material having the higher modulus property will be recovered faster from the deformed shape to the original linear shape than that having the lower modulus.

Also the slopes obtained from the linear curve fitting for the three types of rubber show that it is for (SBR1502> VSL2525> NS116). This can be explained by the improved silica dispersion, which interacts with 1,2unite (butadiene) and leads to the enhanced modulus. This was confirmed by several researchers and confess that the major factors influenced on the modulus are the crosslink density, filler-filler interaction and polymer-filler interaction [15-17]

Instantaneous recovery percent were calculated from the linear curve fitting equations of the lines for all the materials in figures 1,2 and 3 by using the recovery time equal to $1 \times 10^{-6}$ days [18].

Figure(4) displays the instantaneous recovery percent (Ro\%) as a function of aging period. The figure shows that the Ro\% decreases for the three types of SBR compounds as the aging period increases. It also shows that at a certain period the value of R०\% for the three types were arranged as follow (NS116> VSL2525> SBR1502) and this was attributed to the amount of butadiene in the compound.

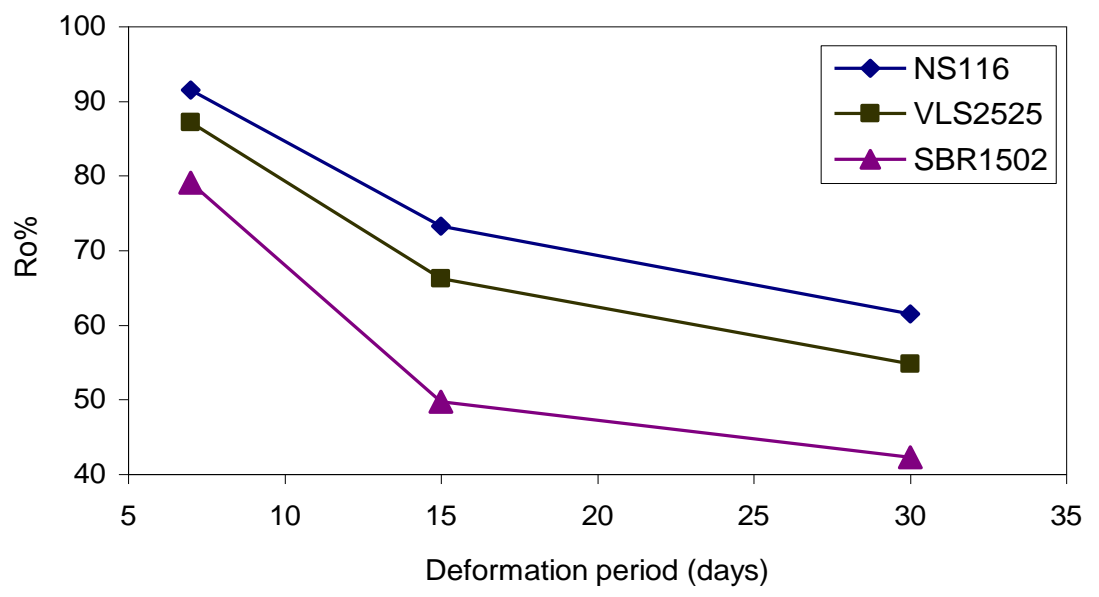

Fig.(4) Instantaneous recovery of different types of SBR versus aging period in circular deformation 
SBR composite type NS116 which has higher recovery percent from circular deformation at room temperature was used to study the effect of different aging temperature on its recovery behaviors.

Figure (5) displays R\% from circular form of NS116 aged at $(60,70,80,90)^{\circ} \mathrm{C}$ for 7 days versus time after the removal from the circular form. The figure shows that $\mathrm{R} \%$ for all samples aged at different temperature increases with the recovery time increment. R\% for samples aged at low temperature is higher than those aged at high temperature. Slopes obtained from the linear curve fitting for samples aged at different temperatures show that the slope increases with aging temperature increment. This behavior is due to formation of new crosslink by thermal aging. level of the increased crosslink density becomes larger as the aging temperature increases.

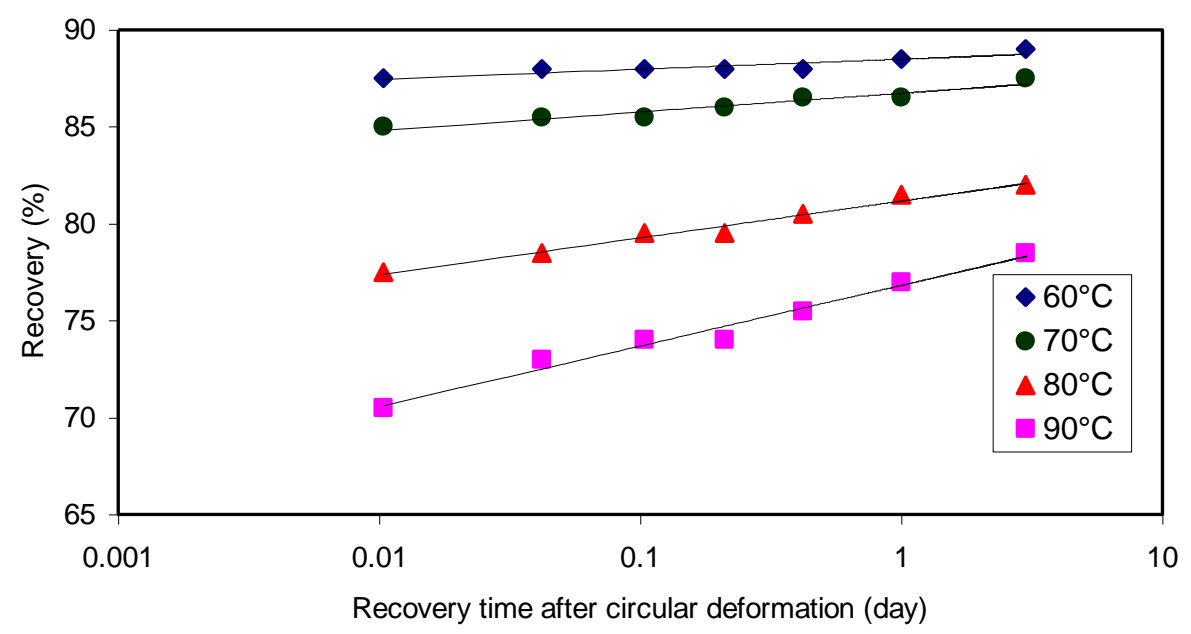

Fig.(5) Recovery percent of NS116 aged at different temp. in circular form versus time after sample release.

Figure (6) displays the relation between the instantaneous recovery percents of NS116 at $1 \times 10^{-6}$ day versus the aging temperature. It is clear that $\mathrm{R} \%$ decreases by aging temperature increment, and this depends on the modulus properties which decreases by aging temperature.

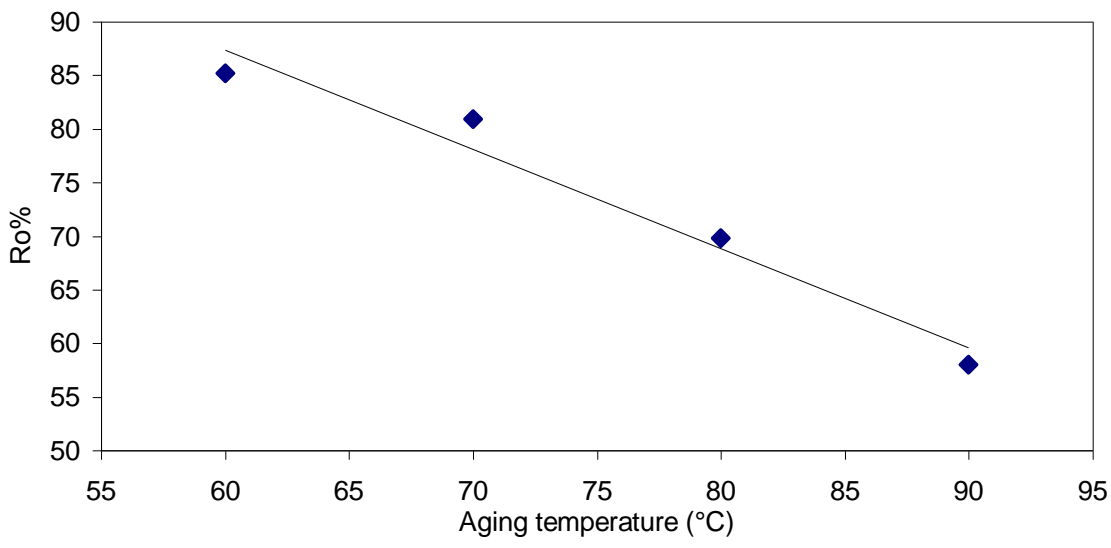

Fig.(6) The relation of instantaneous recovery percent from circular deformation of NS116 with aging temperature 


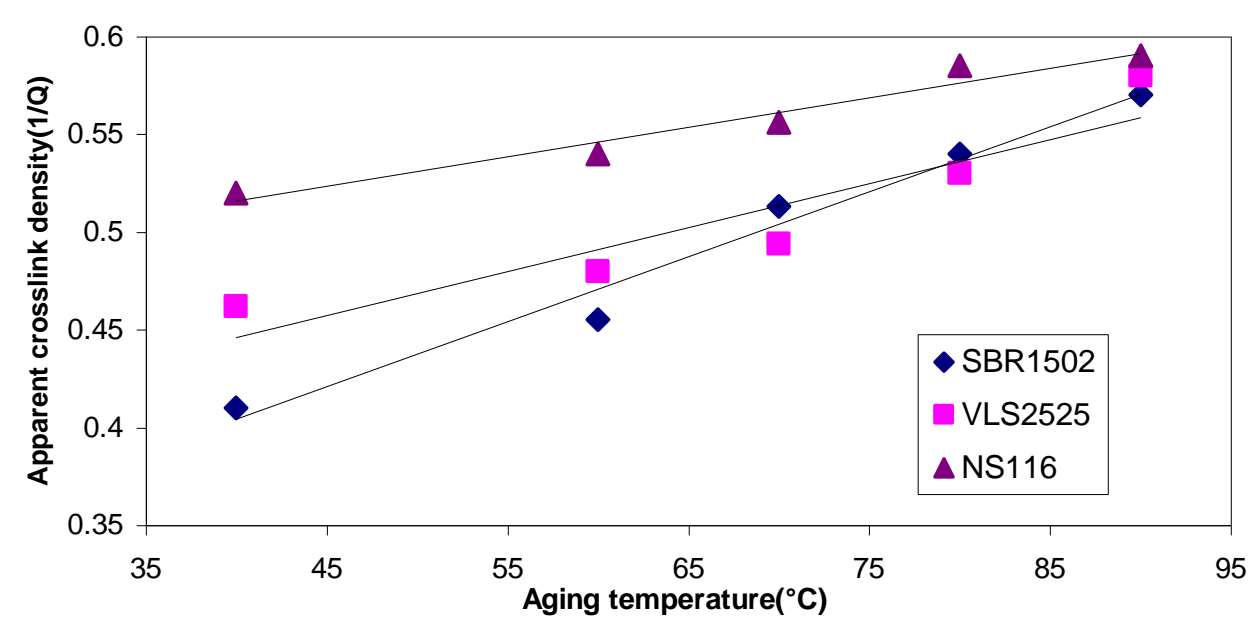

Fig.(7) Variation of the crosslink density of different types of SBR aged for 7 days agenst aging temperature

Figure (7) shows the variation of the apparent crosslink density (1/Q) for the three types of SBR material with the aging temperature. The figure shows that 1/Q increases by the increment of aging temperature and its values is the highest for NS116 and the lowest for SBR1502 as a whole. The slopes obtained from the linear curve fittings for the three types of SBR compound are different within the studied rang of aging temperature. This can be explained with the number of active sites for cross linking reactions, which is allylic carbon. It can lead to conclude that $(1 / \mathrm{Q})$ becomes higher by thermal aging with the increase of the 1,2unit content since the number of cross linking reaction sites increases.

\section{Conclusion}

The research was done on SBR material used as sealant. The results from the experimental data can be concluded as follows:

1. The recovery percent and instantaneous recovery percent from circular form deformation of the samples were inversely proportional to the deformation period. They also increased with the recovery time increment after releasing the samples from the circular form.

2. The values of recovery percent of the three used types of SBR material aged at room temperature with different periods was arranged as follows: NS116>VSL2525>SBR1502 while its rate of change with respect to the deformation time (slopes) was arranged as follows: SBR1502>VSL2525>NS116.

3. Recovery percent and instantaneous recovery percent for NS116 samples aged at different temperature for 7 days was inversely proportional to the temperature degree.

4. Apparent crosslink densities for the three types of SBR material increased with aging temperature increment, and their values for the three types as a whole were arranged as follows: NS116>VSL2525>SBR1502. 


\section{References}

1) Shimadzu, Application News, Thermal analysis $T 115,1$ (2007).

2) R. Comander, Global Rubber (2000) sornia (Canada).

3) N. P. cheremisioff, S. Roy, B. R. Gupta and S. K. De, Elastomere Technology handbook, 635. (1993).

4) Y. C. Ou, Z. Z. Yu, A. Vidal and J. B. Donnet, Rubber Chem. Technol., 67, 834 (1994).

5) S. Wolff and M. J. Wang, Rubber Chem. Technol., 65, 329 (1992).

6) Y. Li, M. J. Wang, T. Zhang, F. Zhang, and X. Fu, Rubber Chem. Technol. 67, 693 (1994).

7) S. seen choi, Bull. Kor. Chem. soc., 21, 628 (2000).

8) S. S. choi, D. H. Han, S.W. Ko, and H. S. Lee, Bull. Kor. Chem. Soc., 26, 1853 (2005).

9) B. Erman and J. E. Mark, Annu. Rev. Phys. Chem., 40, 351, (1989).

10) K. T. Gillen, R. Bernstein, and M. H. Wilson, J. Polym, Deg. Stab., 87, 257 (2005).

11) J. Diez, R. Bellas, J. Lopez, G. Santoro, C. Marco, and G. Ellis, J. Polymer Research, 10, 1007 (2009).

12) H. Ren, $Y$. Qu, and S. Zhaq, Chinese Journal of Chemical Engineering, 14, 93 (2006).

13) A. shavarts, kautshccuk-1 resina, 7, 31 (1957).

14) N. J. Morrison and M. Porter, Rubber chem. Technol., 57, 63 (1984).

15) C. C. Peng, A. Gpfert, M. Drechsler, and V. Abetz, polym. Adv. Technol., 16, 770 (2005).

16) S. S. Ray, J. lnd. Eng. Chem., 12, 811 (2006).

17) F. F. Fang and H. J. choi, J. lnd. Eng. Chem., 12, 843 (2006).

18) ASTM - D. for Thermal Oxidation Aging, 573, 53T, (1957). 